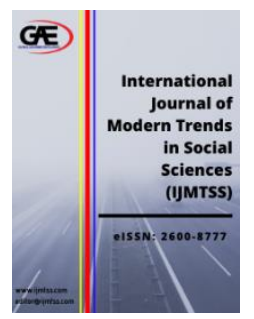

\author{
INTERNATIONAL JOURNAL OF \\ MODERN TRENDS IN \\ SOCIAL SCIENCES \\ (IJMTSS) \\ www.ijmtss.com
}

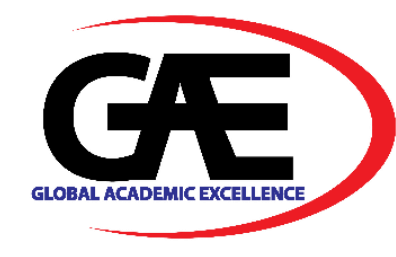

\title{
APPLYING THE ELABORATION LIKELIHOOD MODEL TO ANALYZE THE EFFECTS OF DEPRESSION PUBLIC SERVICE ANNOUNCEMENTS AMONG MALAYSIAN COLLEGE STUDENTS
}

\author{
Yu Fan Jin ${ }^{1}$, Norliana Hashim²* \\ 1 Department of Communication, Universiti Putra Malaysia \\ Email: jinyufan28@gmail.com \\ 2 Department of Communication, Universiti Putra Malaysia \\ Email: h_norliana@upm.edu.my \\ Corresponding Author
}

\section{Article Info:}

Article history:

Received date:02.05.2021

Revised date: 15.06 .2021

Accepted date: 11.08.2021

Published date: 09.09.2021

\section{To cite this document:}

Yu, F. J., \& Hashim, N. (2021). Applying The Elaboration Likelihood Model To Analyze The Effects Of Depression Public Service Announcements Among Malaysian College Students. International Journal of Modern Trends in Social Sciences, 4 (17), 54-73.

DOI: $10.35631 / \mathrm{IJMTSS} .417006$

This work is licensed under CC BY 4.0 (c)

\begin{abstract}
:
As depression became an increasing contributor to the global disease burden, there is a demand for the public to understand depression disorder and reduce stigmatized attitudes about it. Especially, the prevalence of depression among college students is extremely higher than the general population; thus, it is essential to study among college students. Specifically, the utilizing of the health Public Service Announcement (PSA) is aiming to raise public awareness about health issues. Thus, this study emphasized on Depression Public Service Announcement and its effectiveness. By utilizing the Elaboration Likelihood Model (ELM), this study examined the consequences of the dual-process method towards stigmatized attitude changes about depression among students at a Malaysian public university. Cluster sampling technique was used to select respondents and a total of 185 respondents participated in two groups of experiments. Respondents in each group were exposed to two different DPSAs with either high-quality depression messages or low-quality depression messages. Attributional Questionnaire (AQ) was adapted to measure respondents' attitudes toward depression, and a set of questionnaires based on Reynolds's study was applied to evaluate the information processing approach used. Lastly, the results demonstrated that D-PSA with a high-quality message elicits higher elaboration of respondents and less stigmatized attitudes. Conversely, D-PSA with low-quality messages elicits lower elaboration and more stigmatized attitudes about depression.
\end{abstract}

Keywords:

Information Processing, Elaboration Likelihood Model, Depression, Public Service Announcement, Media Psychology 


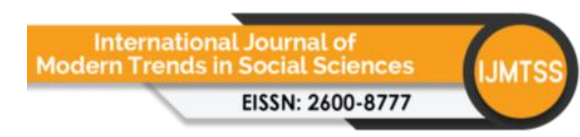

Volume 4 Issue 17 (September 2021) PP. 54-73

DOI 10.35631/IJMTSS.417006

\section{Introduction}

Depression is a remarkable contributor to the global disease burden, which affected more than 264 million people globally across age groups (World Health Organization, 2020). Specifically, the prevalence of depression among college students is extremely higher than the general population (Mishra, Kodwani, Kumar \& Jain, 2018), which the depression awareness among them should be called attentive attention to emphasize. Therefore, there is an immense demand for young people to understand depressive disorder, symptoms, and treatments nicely in order to cope with potential mental health problems in their lives.

Thus, the well-defined and evidence-based public health strategies are intensively needed to raise their awareness, especially Public Service Announcements (PSAs), which are utilized at the core of various public health campaigns effectually (Vecchiato et al., 2010). Fundamentally, health PSAs are functioning to raise public awareness about health subjects (Bratic, Greenberg \& Petersen, 1981), in which the customized content carries informative health messages to educate the receivers adequately. Besides, PSAs also contain the feature of high persuasive emotional effects that stimulate the audience to think about certain issues, therefore, to convince and convert the system of values of the audiences (Terskikh, 2016; Ftanou et al., 2016).

In the context of depression, effective depression Public Service Announcement (D-PSA) is capable of decreasing negative expectations of the audiences (Lienemann \& Siegel, 2018). The utilization of D-PSAs is potentially encouraging audiences to understand depression correctly and decrease their depression stigma steadily. Moreover, people who are suffering from the depressive disorder are motivated to adopt help-seeking attitudes by being exposed to effective D-PSAs properly (Klimes-Dougan \& Lee, 2010); which the directional content of D-PSAs offer professional guidance for patients. Therefore, it is undeniable that D-PSAs help promote depression awareness and knowledge among both ordinary viewers and patients.

With the consequences of the existing and utilization of D-PSAs currently, young people are able to receive health information from D-PSAs, which will cater for their needs. Subsequently, the information processing behavior in D-PSAs would arise in which people process and organize the information using different approaches. To be specific, an information processing approach functions as a framework to perceive and encode the information, thus, evaluating the information within a certain mechanism (Williams, Wasserman \& Lotto, 2003).

However, there are still some people who lack depression-related knowledge and even contain stigmatized attitudes toward depression disorder. A study indicated that $20 \%$ of young respondents said they never heard about the depressive disorder and assumed it as a non-mental disorder (Swannell \& McDermott, 2015). Consequently, limited depression-related knowledge and stigmatized attitudes are significant issues among young people currently. In addition, despite D-PSAs are conducted for the positive intention, some ineffective D-PSAs would generate negative consequences from the impact perspective, which will potentially lead to the increasing stigma and negative attitudes toward depression instead (Siegel, Lienemann \& Tan, 2014) in which the inappropriate content will possibly affect the perception of audiences.

While previous research has investigated the utilization and effectiveness of various genres of PSA (Ahn, Wu, Kelly \& Haley, 2011; Shead, Walsh, Taylor, Derevensky \& Gupta, 2011; Ti, Fast, Small \& Kerr, 2017), meanwhile, PSAs for mental health has also been explored by some 


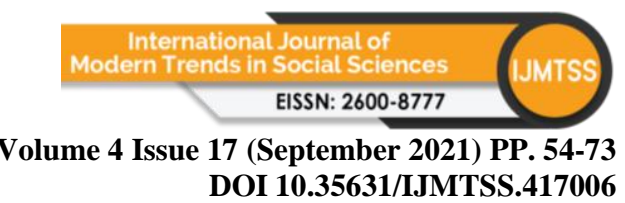

studies (Iles, Seate \& Waks, 2015; Ftanou et al., 2016). However, there are merely research conducted to study Public Service Announcements that focus on depression issues. Moreover, few studies have examined the information processing behavior in PSAs, especially D-PSAs. Lastly, there is barely any research conducted in Malaysia regarding both the D-PSAs and information processing behavior in PSAs. Thus, it is significant for this study to explore how people process information from D-PSAs within different approaches and their perceived attitudes consequently.

\section{Literature Review}

\section{Depression Awareness and Young Generation}

There are various potential factors that would lead to depression among young people. According to a study conducted in Malaysia, using drugs and being bullied are the most influential contributors that cause depression. Otherwise, alcohol use and lack of parental supervision are also associated with depressive disorder among the young generation (Kaur et al., 2014).

Additionally, Hickie et al. (2007) applied the International Depression Literacy Survey (IDLS) in an Australian university to examine their understanding of depression. The result reported that only $20 \%$ of college students concerned common symptoms, behaviors, and experiences of depression. Regarding symptoms of depression, "being sad, down or miserable" was the most recognizable sings among respondents to typify a person with depression.

Specifically, Wilson, Rickwood and Deane (2007) found that majority of high school students were more likely to seek help from informal sources such as family members or friends instead of professional sources. However, different levels of depression (minimal, mild, or moderatesevere) are also an influential factor that could trigger people who are suffering from depression to access related help from different sources accordingly.

\section{Health-related Public Service Announcements}

In order to create people's awareness of health issues, numerous intervention campaigns are applied to achieve their functions, while Public Service Announcement is one of them. PSA emphasized different aspects of health issues to cater for different demands. According to Ftanou et al. (2016), they analyzed suicide prevention Public Service Announcements globally and found that half of the suicide prevention PSAs demonstrated the importance of the life of a suicidal person, around $40 \%$ indicated the suffering from suicidal thoughts, and merely $25 \%$ emphasized that suicide behavior could be prevented.

Additionally, the further impact of PSAs could be varied depending on their emphasis on the content. There is a comparison between two PSAs in which one is recovery-oriented video whereas the another is treatable disease-oriented video, however, aiming at the same function, which is to reduce stigma. It has resulted in that participants who are exposed to recoveryoriented video PSA reduced significant stigmatizing attitudes rather than treatable diseaseoriented video (Corrigan, Powell \& Al-Khouja, 2015). Thus, it is displayed that the effectiveness of PSAs is influenced by the theme chosen.

Besides, the argument quality of the message also has effects on the effectiveness of PSAs. Previous studies explored the effects of both stigmatizing PSA and non-stigmatizing PSA regarding eating disorder, which implied the low-argument quality and high-argument quality Copyright (C) GLOBAL ACADEMIC EXCELLENCE (M) SDN BHD - All rights reserved 
of the PSA accordingly. As a result, this study displayed that low-quality PSA is directly associating with greater feeling of contempt towards people who have eating disorder (Iles, Seate \& Waks, 2015), which means low-argument quality of the message is likely to form negative attitudes toward recipients. Therefore, argument quality is a crucial factor for the evaluation of the effectiveness of PSAs.

\section{Dual-processing Approach}

The dual-processing approach describes that how people think about perceived information and then make decisions. It differentiates two converse ways of thinking about information that are superficial and thoughtful, leading to converse outcomes when they make decisions and solve problems. Generally, there are two representative dual-processing theories, which are Elaboration Likelihood Model (ELM) and Heuristic-Systematic Model (HSM) that have been applied in many studies (Baumeister \& Vohs, 2007).

Both models study cognitive processes from perceived information that range from low-effort thinking to high-effort thinking. High-effort thinking is controlled and intentional thinking that correlates with issue-relevant cognition about the information, which is decided by individuals' ability (knowledge) and motivation (personal involvement). In contrast, low-effort thinking is involuntary thinking that correlates with simple cues and heuristic shortcuts to process messages (Chaiken, 1987; Petty \& Cacioppo, 1986b).

Bhutada, Rollins and Perri (2016) conducted a study that applied the Elaboration Likelihood Model to examine the correlation between advertisements' effectiveness in print direct-toconsumer advertising of prescription drugs and consumers' involvement. The results indicated that high-involvement consumers gave more attention to advertisement effectiveness variables; thus, they displayed stronger prescription drug inquiry intentions compared to lowinvolvement consumers.

Apart from respondents' involvement, the ability is another factor that could influence the dualprocessing approach. According to Chiang and Jackson (2013), they claimed that the level of health literacy would influence respondents' information processing route chosen in direct-toconsumer advertising (DTCA). With higher health literacy, there is more possibility to process information from DTCA deliberately, in contrast, with lower health literacy, people process information depends on simple cues such as the visual of DTCA.

\section{Theoretical Framework}

Petty and Cacioppo (1981a) developed the Elaboration Likelihood Model (ELM) of persuasion, which "provides a fairly general framework for organizing, categorizing, and understanding the basic processes underlying the effectiveness of persuasive communication" (Petty \& Cacioppo, 1984). The term "elaboration" means the recipients engage in issuerelevant thinking that evaluates the message's strength and drawback.

Basically, ELM is functioning to explore how individuals process persuasive messages differently in which two distinct routes are applied separately: the central route and the peripheral route. Firstly, the central route is taken when the recipients have diligent and thoughtful consideration of the information; the argument quality is emphasized in this route, such as the issue-relevant argument of the message (Petty \& Cacioppo, 1981a). By contrast, the peripheral route tends to be taken by the recipients when there are some simple cues in the persuasion message, such as attractive source and source credibility explicitly (Petty \& Copyright (C) GLOBAL ACADEMIC EXCELLENCE (M) SDN BHD - All rights reserved 


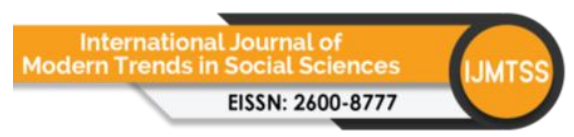

Volume 4 Issue 17 (September 2021) PP. 54-73

DOI 10.35631/IJMTSS.417006

Cacioppo, 1986b). Consequently, the outcomes of these two routes have also differed, which is the different attitudes formed. Attitude change under the central route is enduring and more resistant to future persuasion while those attitude changes under the peripheral route are temporary and more susceptible to future persuasion (Keltner, \& Oveis, 2007).

Additionally, to decide which route is chosen is determined by the extent of elaboration likelihood. When elaboration level is high, the central route is predominated whereas when the level of elaboration is low, the peripheral route is predominated (Petty \& Cacioppo, 1986a). Furthermore, elaboration likelihood is affected by the individual's motivation and ability, which means whether the individuals have motivation and ability to process the message received. Specifically, motivation is associated with personal involvement (relevance) of the issue and need for cognition (desire to think) which would influence message processing. At the same time, the ability to process messages associates with prior knowledge and intelligence of the individuals (Petty \& Cacioppo, 1986a).

Chronologically, apart from the two routes and their influential factors, the routes' consequence is another contributor to the ELM. That is, there are different consequences of attitude changes from different routes chosen. The attitude changes are relatively enduring and resistant to counter-persuasive attempts, and predictive of behaviors for the central route. In comparison, the attitude changes from peripheral route are relatively temporary and susceptible to counter persuasion, and unpredictability of behaviors (Petty, 1994).

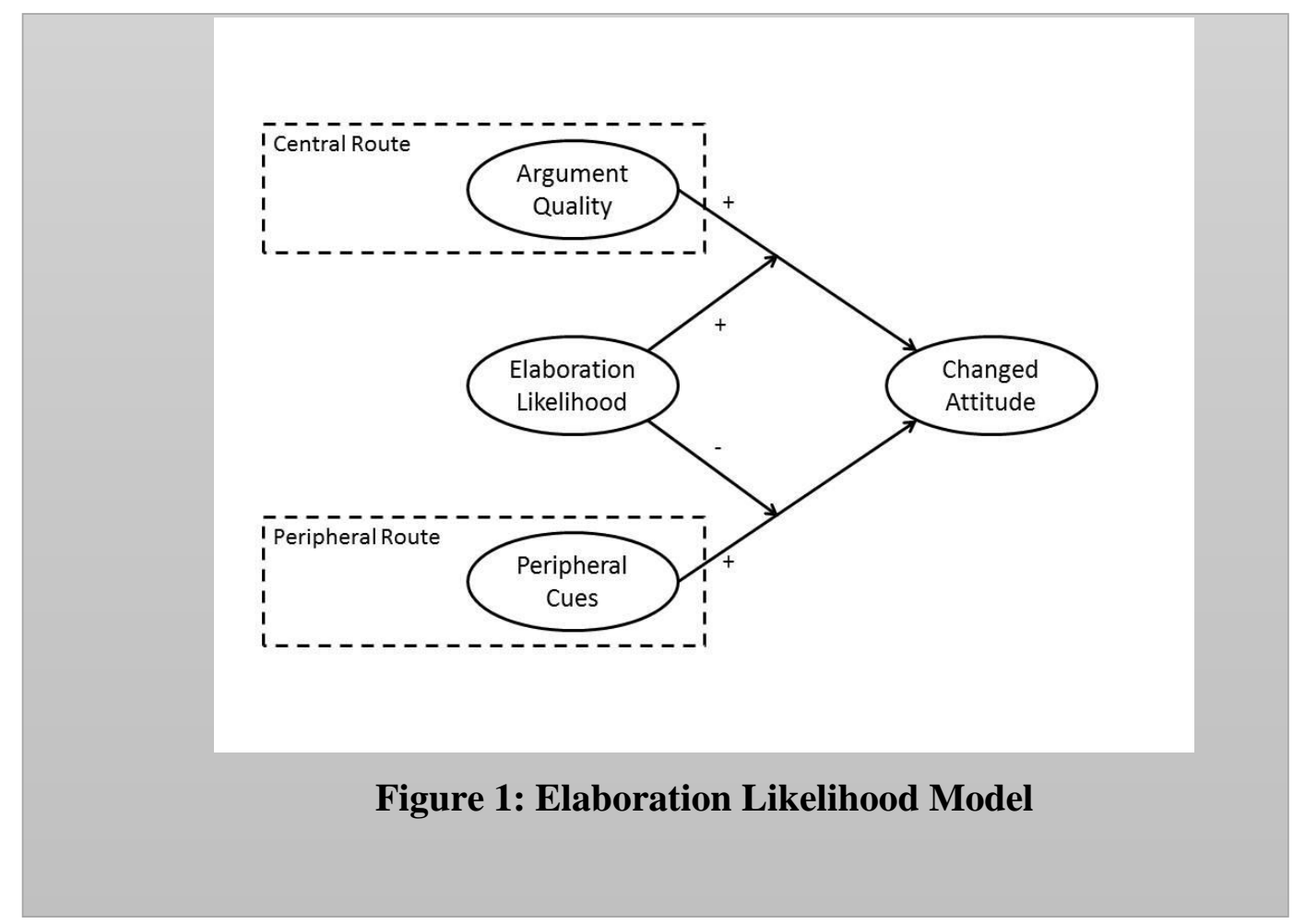

\section{Qualities of D-PSAs (Depression Public Service Announcements)}

The qualities of D-PSAs would influence audiences' attitudes toward depression potentially, while the effective version can disseminate valuable information and drives receivers to form positive attitudes about depression; nevertheless, the ineffective D-PSAs could increase stigmatized attitudes toward audiences (Siegel, Lienemann, \& Tan, 2014). Thus, the quality of D-PSAs is an essential factor that determines the consequences of D-PSAs. 
In addition, Areni and Lutz (1988) stated that the strength of the argument could be manipulated by the quality of the message. Thus, this research designed two D-PSAs with different quality of the message, which are high-quality message D-PSA and low-quality D-PSA to examine its influences on the chosen information processing approach.

\section{Dual Routes}

The central route refers to one of the information processing routes of ELM, which involves thoughtful thinking, careful examination of information, and the evaluation of arguments made in the message (Petty, 1994). Therefore, the use of the central route will lead to the persistence of attitude change and the predictability of subsequent behaviors (Petty, Haugtvedt, \& Smith, 1995). Thus, this leads to the first hypothesis regarding the central route and stigmatized attitude change.

H1: Individuals who are exposed to high-quality D-PSA and use the central route will report less stigmatized attitudes about depression.

Peripheral-route processing involves superficial thinking and simple cues, such as the attractiveness of the message and perceived source credibility (Petty, Cacioppo, \& Heesacker, 1981). As a result, peripheral route used will cause temporary and susceptible attitude change and unpredictable behaviors (Petty, Haugtvedt, \& Smith, 1995). Hence, the second hypothesis was made on the association between peripheral routes and stigmatized attitude change.

H2: Individuals who are exposed to low-quality D-PSA and use the peripheral route will report more stigmatized attitudes about depression.

\section{Stigmatized Attitudes Change}

According to Goffman (1963), stigma is an attribute that is deeply discrediting; it caused an individual to be identified by others in undesirable and stereotyped beliefs rather than normal. It occurs from the social needs to classify individuals for the purpose of identification and socialization. In addition, stigma is relatively a consequence of heuristic processes that people process information by using cognitive shortcuts which are always resulted from various social interactions, such as acquired behaviors from the social group and mass media (Macrae, C. N., Milne, A. B., \& Bodenhausen, G. V., 1994).

Specifically, media portrayal is a significant way to develop stigma by displaying certain characteristics on a certain group of people. Some studies applied stigma as part of the cultivation process, which indicates media portrayals contribute to conveying of information that would considerably influence audiences' cognition of reality (Gerbner, Gross, Morgan, Signorielli, \& Shanahan, 2002). Thus, the contained information of media will influence audiences' stigmatized attitudes with an issue to some extent.

\section{Methodology}

In this study, the quasi-experimental research method was applied, as this method is found to be the best approach to test cause-and-effect relationships by manipulating independent variable on the dependent variable (Grabe \& Westley, 2003; Reeves \& Geiger, 1994). Specifically, this quasi-experimental research consists of pre-test, treatment, and post-test to 
analyze the different attitudes caused by using different information-processing routes (Salkind, 2017).

\section{Participants}

In this article, cluster sampling is applied, in which the intact groups in terms of classes of individuals are randomly selected to study and analyze. Generally, this study involved two groups of participants which is 185 participants in total. For group A, most of the respondents are Malay (49.5\%) and Chinese (43.2\%). $75.8 \%$ of them are female, while $24.2 \%$ are male. Aged 20-25 (82.1\%) is the dominant group in this study. Lastly, there are more than half of the respondents $(51.6 \%)$ are believed in Islam. For group B, female accounts for $80.0 \%$ whereas male accounts for $20.0 \%$. More than half of the respondents are Malay (56.7\%). The majority of the respondents (77.8\%) are from 20-25 age group. Lastly, more than half of the respondents $(61.1 \%)$ are Muslim.

\section{Procedure}

As experimental research, specifically, in a pre-test post-test control group design that aims to study the cause-and-effect relationships, it consists of three parts: pre-test, stimuli, and posttest chronologically.

Basically, the pre-test is about respondents' attitudes toward depression before they are exposed to the stimuli. The Attributional Questionnaire (AQ) was adapted to measure participants' attitudes about depression, which was initially designed to measure stigmatized attitudes towards people with mental illnesses (Corrigan, Markowitz, Watson, Rowan, \& Kubiak, 2003). Specifically, six subscales of the Attributional Questionnaire were adapted which are personal responsibility, pity, anger, fear, helping behavior, and avoidance (Corrigan et al., 2003). For this study's stimuli, two versions of video-format depression public service announcements were designed in which high-quality D-PSA was developed from the existing D-PSA of World Health Organization (2012), whereas the low-quality D-PSA was produced based on Miles (2016). The D-PSA design differed in the quality of the message in order to compare clearly.

Chronologically, two sets of questionnaires were applied after exposure to each stimulus during the post-test stage. Firstly, a set of questions was adapted from previous study regrading elaboration likelihood model (Reynolds, 1997) to evaluate the information processing approach chosen. Secondly, in order to analyze the attitude changes from pre-test to post-test, the Attributional Questionnaire (AQ) was applied to measure attitudes about depression among two groups were measured again.

\section{Data Analysis}

For the pre-test, paired sample t-test was used to measure two groups of respondents' attitudes about depression before being exposed to treatment. For post-test, paired sample t-test was also used to compare elaboration likelihood among the two groups after exposure to different stimuli. Subsequently, a paired-samples t-tests specifically compared attitude changes about personal responsibility, pity, anger, fear, helping behavior, and avoidance of depression from pre-test to post-test. Lastly, Pearson's correlation was applied to study the correlation between the independent variable and dependent variable. The association between each other could be identified by measuring and analyzing the correlation. 


\section{Results and Discussion}

DOI 10.35631/IJMTSS.417006

The study's first objective is to measure two groups of respondents' attitudes about depression before they are exposed to treatment, which is the pre-test stage. Mean results obtained for each subscale of the Attributional Questionnaire are shown in table 1 below. Pity was the subscale with the highest scores (mean=6.23) among six subscales for group A. As for group B, the subscale of pity also reported the highest scores (mean=6.57), which can be concluded that two groups of respondents hold similar stigmatized attitudes about depression regarding pity.

In order to compare attitudes among two groups, paired sample t-tests was used to analyze. According to table 2, there are six pairs of data categorized by six subscales of the Attributional Questionnaire to compare. The significant results obtained for six pairs which are personal responsibility $(\mathrm{p}=0.630)$, pity $(\mathrm{p}=0.231)$, anger $(\mathrm{p}=0.079)$, fear $(\mathrm{p}=0.712)$, helping $(\mathrm{p}=0.117)$, and coercion-segregation $(\mathrm{p}=0.505)$ are greater than 0.05 . Thus, there is no significant difference between group A and group B regarding their attitudes about depression before exposed to the treatment. 
Table 1: Means Obtained for Each Subscale of Attributional Questionnaire (Pre-test)

\begin{tabular}{|c|c|c|c|c|c|c|c|c|c|}
\hline Items & Subscales & & Iin & & lax & Me & an & & D \\
\hline & & A & B & A & B & A & B & A & B \\
\hline It was their own fault for people with depression. & Personal responsibility & 3 & 4 & 10 & 10 & 5.90 & 6.20 & 2.20 & 2.04 \\
\hline $\begin{array}{l}\text { The cause of a person's depression is completely under his or her } \\
\text { control. }\end{array}$ & Pity & 5 & 5 & 9 & 8 & 6.23 & 6.57 & 1.27 & 0.81 \\
\hline I would feel pity for people with depression. & & & & & & & & & \\
\hline $\begin{array}{l}\text { I have sympathy for people with depression. }{ }^{\text {a }} \\
\text { I would feel offended by people with depression. }\end{array}$ & Anger & 2 & 2 & 5 & 8 & 3.80 & 4.73 & 0.80 & 2.08 \\
\hline $\begin{array}{l}\text { I would feel angry by people with depression. } \\
\text { I think people with depression are dangerous than the normal }\end{array}$ & Fear & 2 & 2 & 8 & 7 & 4.10 & 4.27 & 1.76 & 1.79 \\
\hline people. & Helping & 3 & 3 & 9 & 9 & 4.77 & 5.57 & 1.65 & 1.97 \\
\hline $\begin{array}{l}\text { I would feel unsafe around people who with depression. } \\
\text { I would help a person who with depression if he or she asks. }{ }^{\text {a }}\end{array}$ & & & & & & & & & \\
\hline $\begin{array}{l}\text { If I were a landlord, I probably would rent an apartment to people } \\
\text { who with depression. a }\end{array}$ & Coercion-segregation & 4 & 2 & 7 & 9 & 5.20 & 5.57 & 1.15 & 2.50 \\
\hline $\begin{array}{l}\text { I think people with depression pose a risk to their neighbours } \\
\text { unless they are hospitalized. }\end{array}$ & & & & & & & & & \\
\hline I think mental hospital is the best place for people with depression. & & & & & & & & & \\
\hline
\end{tabular}

Min=minimum; $\mathrm{Max}=$ maximum $; \mathrm{SD}=$ standard deviation

${ }^{a}$ Items were reverse-coded. 
Table 2: Paired Sample Test Between Group A and Group B

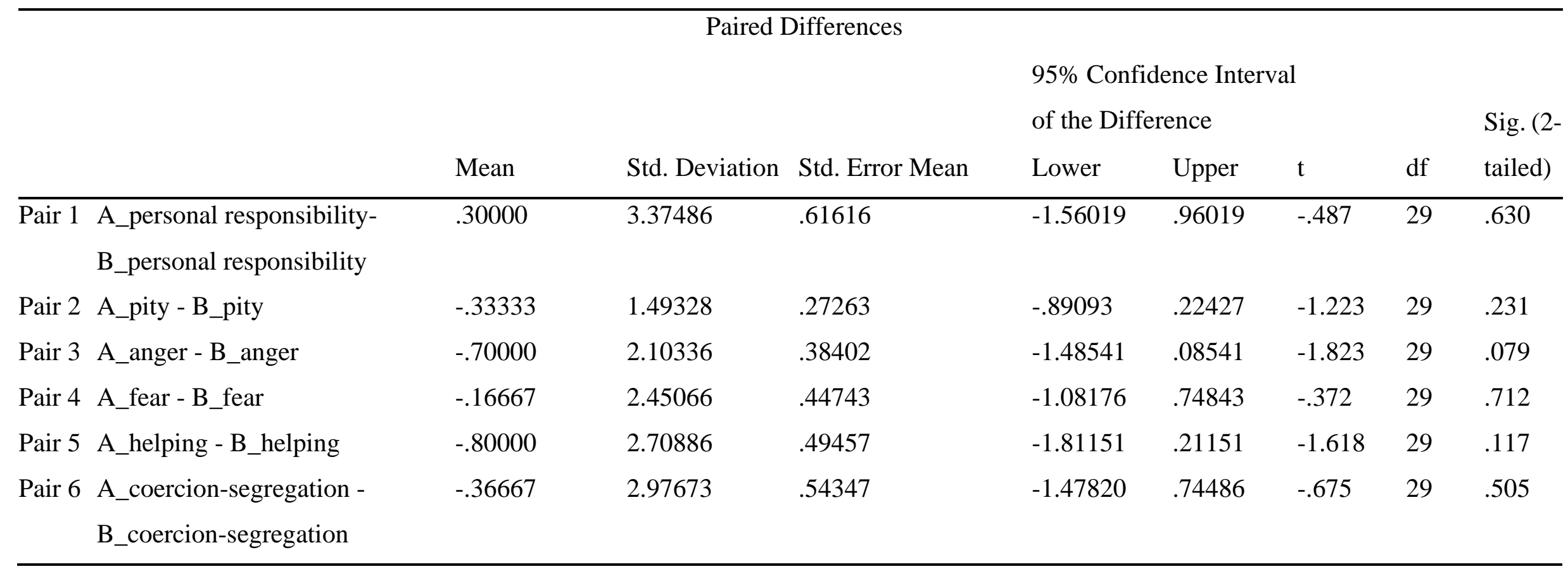


In order to determine the information processing approach applied, the elaboration likelihood was measured. The mean results obtained of elaboration likelihood for the two groups are shown in table 3. The overall mean for group A is $3.60(S D=0.62)$, while group B is 2.39 ( $S D=0.61)$. Moreover, table 4 showed that the significant results are generally less than 0.05 , which means there is a significant difference between the two groups. Thus, it can be concluded that group A reported higher elaboration of message while group B reported lower elaboration of message. Specifically, it means that people exposed to high-quality D-PSA (group A) had higher elaboration than people exposed to low-quality D-PSA (group B) significantly.

Table 3: Mean Obtained for Two Groups

\begin{tabular}{lllll}
\hline Group & Min & Max & Mean & SD \\
\hline Group A & 2.50 & 4.50 & 3.60 & 0.62 \\
Group B & 1.33 & 4.00 & 2.39 & 0.61 \\
\hline
\end{tabular}

Min=minimum; Max=maximum; $\mathrm{SD}=$ standard deviation 


\section{Table 4: Paired Sample Test for Elaboration Likelihood}

Paired Differences

$$
\text { 95\% Confidence }
$$

Interval of the

Std. Std. ErrorDifference Sig. (2-

\begin{tabular}{|c|c|c|c|c|c|c|c|c|}
\hline & Mean & Deviation & Mean & Lower & Upper & $\mathrm{t}$ & df & tailed) \\
\hline$\overline{\text { Pair } 1}$ & I was not really pay attention to the ideas of the video. ${ }^{\text {a }}$ & 1.49482 & .27292 & .64183 & 1.75817 & 4.397 & 29 & .000 \\
\hline Pair 2 & I was trying to analyze the issues in the video. & 1.13664 & .20752 & 1.04224 & 1.89110 & 7.068 & 29 & .000 \\
\hline Pair 3 & I was spending a lot of effort to watch the video. & 1.09334 & .19962 & .25841 & 1.07493 & 3.340 & 29 & .002 \\
\hline Pair 4 & I was searching my mind in response to the ideas. & 1.16264 & .21227 & 1.16586 & 2.03414 & 7.538 & 29 & .000 \\
\hline Pair 5 & $\begin{array}{l}\text { I was distracted by other thoughts not related to the message } 80000 \\
\text { in the video. }{ }^{\mathrm{a}}\end{array}$ & 1.44795 & .26436 & .25933 & 1.34067 & 3.026 & 29 & .005 \\
\hline Pair 6 & I was thinking about the underlying meaning of the message 1.50000 & 1.19626 & .21841 & 1.05331 & 1.94669 & 6.868 & 29 & .000 \\
\hline
\end{tabular}


Lastly, the paired sample t-test is used to measure the stigmatized attitude changes by comparing pre-test and post-test among two groups. For group A, the respondents exposed to high-quality D-PSA reported less stigmatized attitudes about depression from pre-test $(M=30.0, S D=5.83)$ to post-test $(M=28.3, S D=4.35)$. According to table 5 , the difference $(\mathrm{p}=0.17)$ is more than 0.05 that is significant. Specifically, as table 7 showed below, the stigmatized attitude about depression in the subscale of personal responsibility $(M=5.90, S D=2.20 ; M=4.27, S D=1.31)$, pity $(M=6.23, S D=1.27 ; M=$ $5.73, S D=0.94)$ and helping $(M=4.77, S D=1.65 ; M=4.30, S D=1.17)$ decreased from pre-test to post-test.

As for group B, the respondents who are exposed to low-quality D-PSA reported more stigmatized post-test attitudes $(M=32.6, S D=7.13)$ about depression generally than pre-test attitudes $(M=33.2, S D=6.14)$, the significant result showed significantly difference $(\mathrm{p}=0.38)$ according to table 6 . To be specific to the subscales, the table 8 showed that fear $(M=4.27, S D=1.80 ; M=6.10, S D=1.69)$ and coercion-segregation $(M=5.57, S D=2.50 ; M=6.30, S D=1.53)$ are increased considerably between pre-test and post-test 
Table 5: Paired Sample Test of Group A

Paired Differences

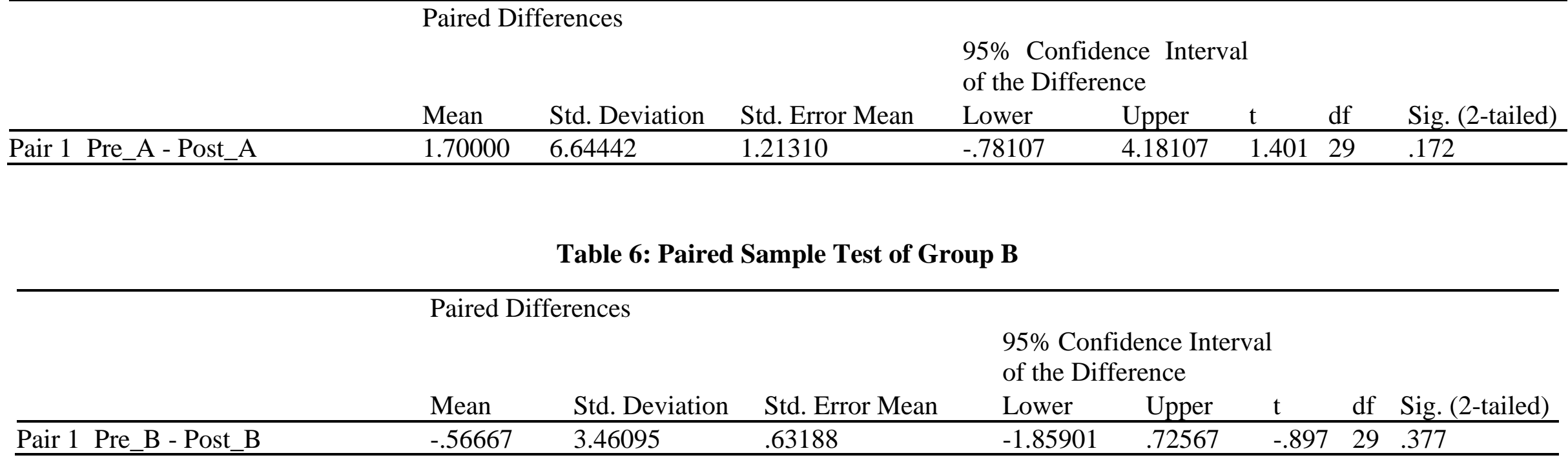


Table 7: Paired Sample Statistics of Group A Mean N Std. Deviation Std. Error Mean

\begin{tabular}{lccccc}
\hline Pair 1 & pre_personal & 5.9000 & 95 & 2.20266 & .40215 \\
& post_personal & 4.2667 & 95 & 1.31131 & .23941 \\
Pair 2 & pre_pity & 6.2333 & 95 & 1.27802 & .23333 \\
& post_pity & 5.7333 & 95 & .94443 & .17243 \\
Pair 3 & pre_anger & 3.8000 & 95 & .80516 & .14700 \\
& post_anger & 3.8667 & 95 & .93710 & .17109 \\
Pair 4 & pre_fear & 4.1000 & 95 & 1.76850 & .32288 \\
& post_fear & 4.8667 & 95 & 1.59164 & .29059 \\
Pair 5 & pre_helping & 4.7667 & 95 & 1.65432 & .30204 \\
& post_helping & 4.3000 & 95 & 1.17884 & .21523 \\
Pair 6 & pre_coercion & 5.2000 & 95 & 1.15669 & .21118 \\
& post_coercion & 5.2667 & 95 & 2.31834 & .42327 \\
\hline
\end{tabular}

EISSN: 2600-8777

Volume 4 Issue 17 (September 2021) PP. 54-73 DOI 10.35631/IJMTSS.417006

Table 8: Paired Sample Statistics of Group B

\begin{tabular}{clllll} 
& & Mean & N & Std. Deviation & $\begin{array}{l}\text { Std. Error } \\
\text { Mean }\end{array}$ \\
\hline Pair 1 & pre_personal & 6.2000 & 90 & 2.04096 & .37263 \\
& post_personal & 5.0667 & 90 & 1.94641 & .35536 \\
Pair 2 & pre_pity & 6.5667 & 90 & .81720 & .14920 \\
& post_pity & 6.0667 & 90 & .86834 & .15854 \\
Pair 3 & pre_anger & 4.5000 & 90 & 1.88917 & .34491 \\
& post_anger & 4.1333 & 90 & 1.38298 & .25250 \\
Pair 4 & pre_fear & 4.2667 & 90 & 1.79911 & .32847 \\
& post_fear & 6.1000 & 90 & 1.68870 & .30831 \\
Pair 5 & pre_helping & 5.5667 & 90 & 1.97717 & .36098 \\
& post_helping & 5.5667 & 90 & 1.10433 & .20162 \\
Pair 6 & pre_coercion & 5.5667 & 90 & 2.50080 & .45658 \\
& post_coercion & 6.3000 & 90 & 1.53466 & .28019 \\
\hline
\end{tabular}




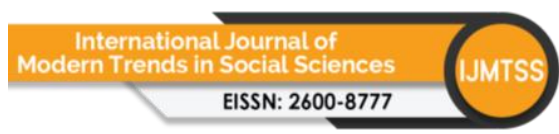

Volume 4 Issue 17 (September 2021) PP. 54-73

DOI 10.35631/IJMTSS.417006

Pearson's Correlation Coefficient method is used to measure the relationship or association between two or more variables. The results of correlation coefficient in this study are significant since there are two asterisks $(*)$, which SPSS would mark two asterisks to represent a 0.01 significant level. Thus, the significant correlation interprets a moderate negative correlation between central route and less stigmatized attitude $(r=-0.494, p=0.003)$. Therefore, it can be concluded that the higher elaboration likelihood, the lower stigmatized attitude. The result showed a very weak negative correlation between peripheral route and more stigmatized attitude $(\mathrm{r}=-0.084, \mathrm{p}=0.658$, which means that peripheral route would not affect the stigmatized attitude significantly.

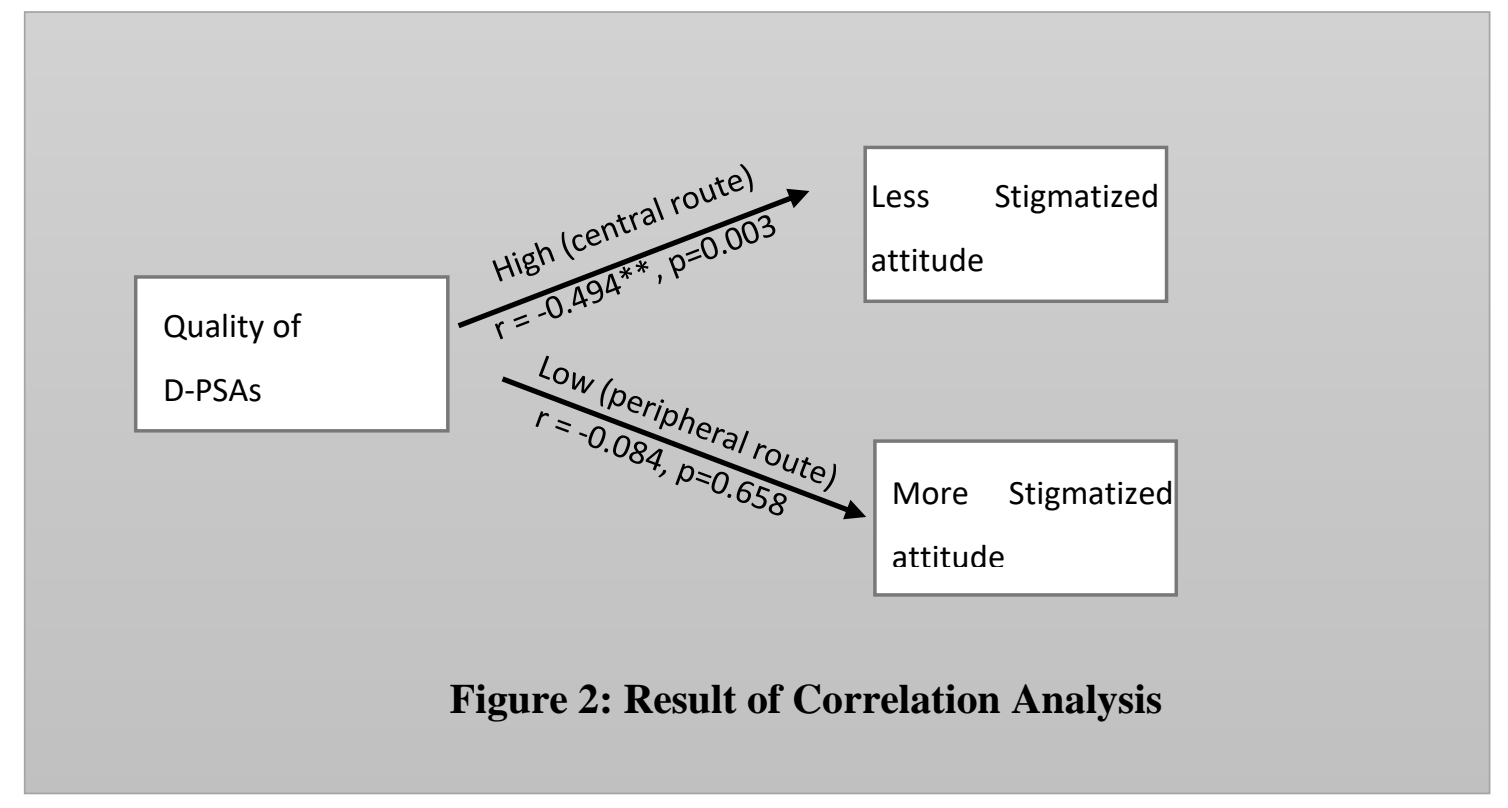

On the other hand, two hypotheses were proposed in this study: individuals exposed to highquality D-PSA and use central route will report less stigmatized attitudes about depression (H1). This hypothesis is valid which is evidenced by the findings of study ( $\mathrm{r}=-0.494, \mathrm{p}=0.003)$. Thus, the research rejects the null hypothesis. The second hypothesis is that individuals exposed to low-quality D-PSA and use peripheral route will report more stigmatized attitudes about depression $(\mathrm{H} 2)$. This hypothesis is invalid since the data analyzed $(\mathrm{r}=-0.084, \mathrm{p}=0.658)$ showed that $\mathrm{p}$-value is greater than the significant level. Thus, the research failed to reject the null hypothesis.

\section{Conclusion}

Overall, this thesis was originated from the dual-processing approach of Elaboration Likelihood Model to study the relationship between message quality of PSA, information processing approach and stigmatized attitude changes.

The result showed that two groups of respondents hold similar attitudes toward depression before viewing D-PSA, which the subscale of pity affected stigmatized attitude remarkably. Different qualities of D-PSA could affect different elaboration likelihood, which respondents who viewed high-quality D-PSA had higher elaboration than respondents who viewed lowquality D-PSA. 
Different qualities of D-PSA could lead to different stigmatized attitude changes, which respondents who are exposed to high-quality D-PSA reported less stigmatized attitude significantly whereas respondents who are exposed to low-quality D-PSA reported more stigmatized attitude slightly, that means low-quality D-PSA would not lead to more stigmatized attitude entirely, the low-quality D-PSA still works for decreasing stigmatized attitudes about depression.

\section{Limitations and Suggestions}

This research has been conducted according to the intended design and expectations as possible. However, some problems still occurred due to the complicated experimental design and force majeure factors. Firstly, this study was a quasi-experimental design that requires careful conducting of every step, however, due to the outbreaking of covid-19 during the data collecting period, the researcher was not able to assign the respondents into two groups accurately as expected. Thus, some mistakes may occur due to the uncontrollability. Secondly, due to the time limitation, there were only 185 respondents, and all of them were from faculty of modern languages and communication. Thus, the results of this study cannot be generalized to the entire undergraduate students in Malaysia since other faculties and other universities did not involve in.

There are few suggestions for future research regarding the experimental design and stimuli design to ensure the accuracy of research. Firstly, the respondents' assignment should be accurate according to the necessary conditions, which is to fulfill the requirement of quasiexperimental design. Besides, future research should involve a larger and more diverse population of respondents so that the study result could be generalized to the entire Malaysian context. In addition, the perceived quality of the video should be measured for future research according to a relevant scale, which is to ensure the design of video could meet the expectations of the study effectively and accurately. Lastly, future research could apply the Elaboration Likelihood Model to different media fields and study the relationship between various media and people's information processing behavior creatively.

\section{Acknowledgement}

To whom suffer from depression, I know you are the most tender people in the world because you always prioritize others' feelings instead of yours; you always think you are not good enough, but I wish you to know that you have no obligation to be perfect and omnipotent. YOU ARE WHO YOU ARE, and you deserve all the sweetest things in the world. I'll always stand by you, and lastly, this too shall pass.

\section{References}

Ahn, G. Y., Wu, L., Kelly, S., \& Haley, E. (2011). A qualitative study of college student responses to conflicting messages in advertising: Anti-binge drinking public service announcements versus wine promotion health messages. Int J Public Health, 56, 271279. DOI: 10.1007/s00038-010-0217-5

Bhutada, N. S., Rollins, B. L., \& Perri, M. (2016). Impact of animated spokes characters in print direct-to-consumer prescription drug advertising: An elaboration likelihood model approach. Health Communication. DOI: 10.1080/10410236.2016.1138382

Bratic, E., Greenberg, R., \& Petersen, P. (1981). HMTS: Improving the quality of public service announcements through standardized pretesting. Journal of the Academy of Marketing Science, 9 (1), 40-51. 
Chaiken, S. (1987). The heuristic model of persuasion. In M. P. Zanna, J. M. Olson, \& C.P. Herman (Eds.), Social influence: The Ontario Symposium. Hillsdale, NJ: Lawrence Erlbaum Associates.

Chiang, K. P., \& Jackson, A. (2013). Health literacy and its outcomes: Application and extension of elaboration likelihood model. International Journal of Healthcare Management, 6(3), 152-157. DOI: 10.1179/2047971913Y.0000000041

Corrigan, P., Markowitz, F. E., Watson, A., Rowan, D., \& Kubiak, M. A. (2003). An attribution model of public discrimination towards persons with mental illness. Journal of Health and Social Behavior, 44 (2), 162-179. DOI: https://doi.org/10.2307\%2F1519806

Corrigan, P. W., Powell, K. J., \& Al-Khouja, M. A. (2015). Examining the impact of Public Service Announcements on help seeking and stigma: Results of a randomized controlled trial. The Journal of Nervous and Mental Disease, 203 (11). DOI:10.1097/NMD.0000000000000376

Ftanou, M., Cox, G., Nicholas, A., Spittal, M. J., Machlin, A., Robinson, J., \& Pirkis, J. (2016). Suicide prevention public service announcements (PSAs): Examples from around the world. Health Communication. DOI: 10.1080/10410236.2016.1140269

Gerbner, G., Gross, L., Morgan, M., Signorielli, N., \& Shanahan, J. (2002). Growing up with television: Cultivation processes. In J. Bryant \& D. Zillman (Eds.), Media effects: Advances in theory and research. Mahwah, NJ: Lawrence Erlbaum Associates.

Goffman, E. (1963). Stigma: Notes on the management of spoiled identity. Englewood Cliffs, NJ: Prentice Hall.

Grabe, M. E., \& Westley, B. H. (2003). The controlled experiment. In G. H. Stempel III, D. H. Weaver, \& G. C. Wilhoit (Eds.), Mass communication research and theory (pp. 267298). Boston: Allyn and Bacon.

Hickie, I. B., Luscombe, G. M., Davenport, T. A., Burns, J. M., \& Highet, N. J. (2007). Perspectives of young people on depression: awareness, experiences, attitudes and treatment preferences. Early Intervention in Psychiatry, 1(4), 333-339. DOI:10.1111/j.1751-7893.2007.00042.X

Iles, I. A., Seate, A. A., \& Waks, L. (2015). Eating disorder public service announcements: Analyzing effects from an intergroup affect and stereotype perspective. Health Education, 116 (5), 476-488. DOI 10.1108/HE-07-2015-0019

Kaur, J., Cheong, S. M., Mahadir Naidu, B., Kaur, G., Manickam, M., Mat Noor, M., Ibrahim, N., \& Rosman, A. (2014). Prevalence and Correlates of Depression Among Adolescents in Malaysia. Asia Pacific Journal of Public Health, 26(5), 53S-62S. DOI: $10.1177 / 1010539514544356$

Keltner, D., \& Oveis, C. (2007). Elaboration likelihood model. In F. B. Roy \& D. V. Kathleen, (Eds.), Encyclopedia of social psychology (pp. 280-283). London, UK: SAGE Publications.

Klimes-Dougan, B., \& Lee, C. Y. (2010). Suicide prevention public service announcements: perceptions of young adults. Crisis, 31(5), 247-54. DOI: 10.1027/0227-5910/a000032.

Lienemann, B. A., \& Siegel, J. T. (2018). Increasing help-seeking outcomes among people with elevated depressive symptomatology with public service announcements: An examination of functional matching and message sidedness. Journal of Health Communication, 23, 28-39. DOI: https://doi.org/10.1080/10810730.2017.1396630

Macrae, C. N., Milne, A. B., \& Bodenhausen, G. V. (1994). Stereotypes as energy-saving devices: A peek inside the cognitive toolbox. Journal of Personality and Social Psychology, 66(1), 37. 
Miles, S. A. (2016). A dual-process approach to stigma reduction using online, user-generated narratives in social media messages (Doctoral dissertation). Retrieved from Proquest Dissertations and Theses.

Mishra, S. K., Kodwani, A. D., Kumar, K. K., \& Jain, K. K. (2018). Linking loneliness to depression: A dynamic perspective. Benchmarking: An International Journal 25 (7). DOI: $10.1108 / \mathrm{BIJ}-10-2016-0158$

Petty, R. E. (1994). Two routes to persuasion: State of the art. International Perspectives on Psychological Science, 2, 229-247.

Petty, R. E., \& Cacioppo, J. T. (1981a). Attitudes and persuasion: Classic and contemporary approaches. Dubuque, IA: Wm. C. Brown.

Petty, R. E., \& Cacioppo, J. T. (1984). Source factors and the elaboration likelihood model of persuasion. Advances in Consumer Research, 11(1), 668-672.

Petty, R. E., \& Cacioppo, J. T. (1986a). Communication and persuasion: Central and peripheral routes to attitude change. New York: Springer-Verlag New York Inc.

Petty, R. E., \& Cacioppo, J. T. (1986b). The elaboration likelihood model of persuasion. In L. Berkowitz (Ed.), Advances in experimental social psychology (pp. 123-205). New York: Academic Press.

Petty, R. E., Cacioppo, J. T., \& Heesacker, M. (1981). Effects of rhetorical questions on persuasion: A cognitive response analysis. Journal of Personality and Social Psychology, 40, 434-440.

Petty, R. E., Haugtvedt, C., \& Smith, S. M. (1995). Elaboration as a determinant of attitude strength: Creating attitudes that are persistent, resistant, and predictive of behavior. In R. E. Petty \& J. A. Krosnick (Eds.), Attitude strength: Antecedents and consequences. Mahwah, NJ: Lawrence Erlbaum Associates.

Reynolds, R. A. (1997). A validation test of a message elaboration measure, Communication Research Reports, 14(3), 269-278. DOI: 10.1080/08824099709388670

Salkind, N. J. (2017). Exploring Research (9th ed.). England: Pearson.

Shead, N. W., Walsh, K., Taylor, A., Derevensky, J. L., \& Gupta, R. (2011). Youth gambling prevention: Can public service announcements featuring celebrity spokespersons be effective?. Int J Ment Health Addiction, 9, 165-179. DOI: 10.1007/s11469-009-9260$\mathrm{y}$

Siegel, J. T., Lienemann, B. A., \& Tan, C. N. (2014). Influencing help-seeking among people with elevated depressive symptomatology: Mistargeting as a persuasive technique. Clinical Psychological Science, 3(2), 242-255. DOI: 10.1177/2167702614542846

Swannell, E. J., \& McDermott, M. R. (2015). Measuring and predicting mental health literacy for depression. International Journal of Mental Health Promotion,17 (5), 293-311. DOI: http://dx.doi.org/10.1080/14623730.2015.1089010

Terskikh, M. V. (2016). Public service announcements and their influence upon system of values of children (research of concept of "family" formation). Procedia- Social and Behavioral Sciences 233, 133 - 138. DOI: 10.1016/j.sbspro.2016.10.168

Ti, L., Fast, D., Small, W., \& Kerr, T. (2017). Perceptions of a drug prevention public service announcement campaign among street-involved youth in Vancouver, Canada: a qualitative study. Harm Reduction Journal, 14 (3). DOI: 10.1186/s12954-017-0132-7

Vecchiato, G., Astolfi, L., Cincotti, F., Fallani, F. D. V., Sorrentino, D. M., Mattia, D., ... Babiloni, F. (2010). Patterns of cortical activity during the observation of Public Service Announcements and commercial advertisings. Nonlinear Biomedical Physics, 4 (1).

Williams, P. G., Wasserman, M. S., \& Lotto, A. J. (2003). Individual differences in self assessed health: An information-processing investigation of health and illness cognition. Health Psychology, 22 (1), 3-11. DOI: 10.1037/0278-6133.22.1.3 
Volume 4 Issue 17 (September 2021) PP. 54-73

DOI 10.35631/IJMTSS.417006

Wilson, C. J., Rickwood, D., \& Deane, F. P. (2007). Depressive symptoms and help-seeking intentions in young people. Clinical Psychologist, 11,98-107. DOI: $10.1080 / 13284200701870954$.

World Health Organization. (2012). I had a black dog, his name was depression. Retrieved from https://www.youtube.com/watch?v=XiCrniLQGYc

World Health Organization. (2020). Depression. Retrieved from https://www.who.int/newsroom/fact-sheets/detail/depression 